\title{
Design para saúde e qualidade de vida: desenvolvimento e avaliação de requisitos de projeto para fone de ouvido inclusivo
}

\author{
Cunha, Julia M. ${ }^{\text {; }}$. D. Merino, Giselle S. ${ }^{\text {b } ~ \& ~ D . ~ M e r i n o, ~ E u g e n i o ~ A . ~}{ }^{\text {c }}$ \\ ${ }^{a}$ Universidade Federal de Santa Catarina, Brazil.juliamarinac@gmail.com \\ ${ }^{\mathrm{b}}$ Universidade Federal de Santa Catarina, Brazil. gisellemerino@gmail.com \\ ${ }^{\mathrm{c}}$ Universidade Federal de Santa Catarina, Brazil. eugenio.merino@ufsc.br
}

\begin{abstract}
Resumo
Os casos de Perda Auditiva Induzida por Ruído (PAIR) entre crianças e adolescents aumentaram 30\% nos últimos 30 anos, segundo Shargorodsky (2010). Algumas pesquisas (ZHAO et al, 2012. HODGETTS; RIEGER; SZARKO, 2007) indicam que esse aumento pode estar relacionado ao uso de dispositivos pessoais de áudio (Music Induced Hearing Loss (MIHL), como fones de ouvido, que associado a outros fatores, como o tempo de exposição e a intensidade sonora, elevam o risco de perda auditiva. Associado a este problema identifica-se a exclusão vivenciada por usuários de aparelho auditivo que tem dificuldades de utilizar fones de ouvido, devido à inadaptabilidade dos produtos à utilização simultânea.
\end{abstract}

Objetiva-se com esta pesquisa definir os requisitos de projeto que possibilitem a criação de um produto (fone de ouvido) que atenda também os usuários de aparelho auditivo. Para esta finalidade foram consideradas as áreas de ergonomia, usabilidade, design inclusivo para um projeto centrado no usuário que vise proteção da saúde e melhoria da qualidade de vida dos mesmos. Como forma de verificar a viabilidade dos requisitos foi desenvolvido um protótipo funcional, submetido a testes de ruído para aferir sua performance.

A pesquisa foi dividida em duas etapas, uma de cunho teórico que buscou levantar e analisar na literatura os temas relacionados e uma segunda etapa, de cunho prático, onde foram definidos os requisitos e realizado o teste com o protótipo funcional. Em relação a etapa prática, foi utilizado como referência o GODP (Guia de Orientação para o Desenvolvimento de Projetos).

A partir da definição dos requisitos foi desenvolvido um fone de ouvido que, potencialmente, limita a intensidade sonora do som reproduzido e possibilita também a utilização por usuários de aparelho auditivo. Por meio de um protótipo funcional realizouse uma avaliação de nivvel de pressão sonora do fone de ouvido projetado, onde obteve-se o máximo de $73 \mathrm{~dB}$ nas frequências entre 1300 e $1400 \mathrm{~Hz}$, na reprodução de ruído branco. Considerando os tons puros, o nivel de pressão sonora atingiu seu maior valor na frequência 1000Hz, sendo 96,92 dBa. Estes resultados demostram que os requisitos, bem como o produto desenvolvido apresenta um desempenho adequado atendendo as exigências dos usuários. 
Design para saúde e qualidade de vida: desenvolvimento e avaliação de requisitos de projeto para fone de ouvido inclusivo.

A pesquisa possibilitou demonstrar o potencial do design quando aplicado para melhoria da saúde, bem-estar e qualidade de vida das pessoas. Salientando a importância de projetos centrados no usuário, que consideram as pessoas com suas diversas habilidades e capacidades para a geração de produtos que satisfaçam as reais necessidades dos usuários.

Palavras-chave: Fone de ouvido, Perda auditiva, Saúde, Design, Ergonomia.

\begin{abstract}
The number of cases of Noise Induced Hearing Loss (NIHL) among children and teenagers increased by $30 \%$ over the past 30 years, according to Shargorodsky (2010). Some researches (ZHAO et al, 2012. Hodgetts; RIEGER; SZARKO, 2007) indicate that this increase may be related to the use of personal audio devices (Music Induced Hearing Loss -MIHL), such as headphones, which together with other factors such as exposure time and sound levels, increase the risk of hearing loss. Associated with this issue, is identified the exclusion experienced by hearing aid users who have trouble using headphones due to the products inadaptability for simultaneous use.
\end{abstract}

The purpose is to achieve with this research the definition of project requirements that enable the creation of a product (headphone) that also meets the users of hearing aids. For this purpose we have considered, ergonomics, usability and inclusive design for a usercentered product aimed at hearing healthcare and improving the users quality of life. In order to check the requirements feasibility, it was developed a prototype, subjected to a sound pressure level evaluation to measure its performance.

The research was divided into two stages, a theoretical one which sought to address and analyze the literature related themes and a second stage of practical nature, where the requirements were defined and the test with the prototype was performed. Regarding the practical stage, it was guided by the GODP (Guidance for Project Development) methodology.

Based on the requirements was developed a headphone that potentially limits the sound level of the reproduced sound and also allows the use for hearing aids users. The prototype was submitted to a sound pressure level evaluation, where the maximum of $73 d B$ at frequencies between 1300 and $1400 \mathrm{~Hz}$ was obtained, during the reproduction of white noise. Considering the pure tones, the sound pressure level was reached in its highest value with the frequency of $1000 \mathrm{~Hz}$, being $96.92 \mathrm{dBA}$. These results show that the requirements, and the product had a satisfactory performance, meeting the users demands.

The research allowed to demonstrate the design potential when applied to improve the health, well-being and people's quality of life. Highlighting the importance of user focused projects, who consider people with their diverse skills and capabilities to generate products that meet the users real needs.

Keywords: Headphones, Hearing loss, Health, Design, Ergonomics. 


\section{Introdução}

A comunicação entre os seres humanos é o que impulsiona o desenvolvimento da sociedade desde os tempos antigos; a linguagem oral foi o modo mais rápido encontrado pela civilização para a troca de informações, esta envolve dois sentidos, a fala e a audição. A audição é o sentido responsável pela recepção dos sons, é o sentido que possibilita a aquisição da língua oral, fisiologicamente é a consciência da vibração interpretada como som pelo ouvido humano.

O ser humano mesmo antes do nascimento, é exposto à diversos fatores de risco que podem ocasionar a deficiência auditiva. Segundo Shield (2006), as perdas auditivas estão entre as deficiências crônicas mais comuns, atingindo uma em cada 6 pessoas.

Cerca de 15 milhões de brasileiros possui alguma deficiência auditiva. Segundo Palma (1999), a Perda Auditiva Induzida pelo Ruído também conhecida como PAIR é uma das causas mais comuns de perda auditiva sensorioneural encontrada na prática clínica.

A PAIR, segundo o Ministério da Saúde (2006) é definida como a diminuição gradual da acuidade auditiva decorrente da exposição contínua em níveis elevados de pressão sonora.

No Brasil cerca de 1 milhão de crianças e jovens de até 19 anos possuem deficiência auditiva parcial (SBO, 2014; IBGE, 2010). Segundo pesquisas, o aumento do número de casos de PAIR entre crianças e adolescentes é relacionada ao uso de fones de ouvido (ZHAO et al, 2012. HODGETTS; RIEGER; SZARKO, 2007. HAINES et al, 2011. LEVEY; LEVEY; FLIGOR, 2011). Referindo-se recentemente à nomenclatura específica, Perda Auditiva Induzida pela Música (Music Induced Hearing Loss- MIHL) (MORATA, 2007).

Segundo a OMS, 1,1 bilhão de jovens estão em risco de adquirir perda auditiva devido ao uso indevido de dispositivos de áudio. Esse aumento pode ser atribuído também ao crescimento da indústria de dispositivos pessoais de música (personal listening devices- PLDs) e desenvolvimento de tecnologia na área (SHARGORODSKY, 2010).

A perda auditiva induzida por música em volume elevado, segundo Vogel et al (2008), pode estar se desenvolvendo para um problema social e de saúde pública. Os níveis de som dos fones de ouvido da maioria dos dispositivos comercializados, são altos o bastante para prejudicar a audição com algumas horas de uso (KIM et al, 2009).

Diversos fatores relacionam-se diretamente à MIHL, como a intensidade sonora, o tempo de exposição e o dispositivo utilizado (Liang et al, 2012). Consequentemente, o tipo e a configuração do fone de ouvido utilizado afetam estas variáveis (HODGETTS; RIEGER; SZARKO, 2007; LIANG, 2012).

Os efeitos da exposição à sons em volume elevado são cumulativos e podem ocorrer após anos de exposição contínua, por isso a dificuldade de conscientização dos jovens para a mudança de hábitos, as consequências não são notadas imediatamente (ZHAO, 2012).

A tecnologia assistiva pode ser definida como uma esfera do conhecimento interdisciplinar que envolve produtos, recursos, metodologias, práticas e serviços que possuem como objetivo promover a funcionalidade de pessoas com deficiência ou incapacidade, oferecendo bem estar, autonomia e qualidade de vida (BRASIL, Comitê de ajudas técnicas, 2009). O design, juntamente com a ergonomia, envolve-se no projeto de tecnologias assistivas partindo da relação da pessoa com deficiência e o objeto assistivo, buscando projetar produtos que satisfaçam as necessidades e desejos do ser humano, sendo assim um Projeto Centrado no Usuário. (MAIA; NIEMEYER; FREITAS, 2010). 
Design para saúde e qualidade de vida: desenvolvimento e avaliação de requisitos de projeto para fone de ouvido inclusivo.

Inclui-se como tecnologia assistiva, os aparelhos auditivos. Inserido neste aspecto, pontua-se a incompatibilidade do uso de aparelho auditivo concomitantemente com fones de ouvido. Sendo assim, são privados do uso de fones de ouvido, usuários de aparelho auditivo.

Pontuam-se assim as problemáticas em questão:

- O uso de fones de ouvido como fator de risco para a perda auditiva.

- A impossibilidade de uso de fones de ouvido por usuários de aparelho auditivo: a privação de uso de um produto de acordo com as capacidades do usuário vai contra os preceitos de design universal e inclusivo.

Determina-se como objetivo geral da pesquisa, a definição de requisitos para o desenvolvimento de um produto que reduza os riscos à saúde do usuário, prevenindo danos ao sistema auditivo, e permita sua utilização pelo utente de aparelho auditivo. Especificamente:

- identificação das problemáticas relacionadas ao uso do fone de ouvido com a perda auditiva, por meio do levantamento bibliográfico;

- identificação da relação entre usuários de aparelho auditivo e a utilização -ou impossibilidade- de fones de ouvido;

- definição dos requisitos de projeto com foco no usuário, para o desenvolvimento de um produto que evite o dano a audição do utilizador e possa ser inclusivo para usuários de aparelho auditivo;

- realização de teste com protótipo gerado a partir dos requisitos.

\section{Procedimentos Metodológicos}

Considerando a caracterização geral da pesquisa, quanto a natureza pode ser configurada como teóricoaplicada, em relação ao conteúdo, pode ser classificado como artigo de análise onde os elementos são analisados em relação ao todo (MARCONI, 2003).

Referente aos objetivos, a pesquisa pode ser caracterizada como exploratória, constituindo um aprimoramento de ideias sobre o assunto em questão (GIL, 2002). De acordo com os procedimentos técnicos, caracteriza-se como pesquisa bibliográfica, (GIL, 2002).

Divide-se a pesquisa em duas etapas principais:

Etapa 1: etapa teórica onde apresenta-se a fundamentação, com relação aos métodos pode-se descrever, pesquisas nas bases de dados Science Direct, PubMed, Web of Science,

Google Acadêmico, Periódicos Capes e Biblioteca Digital de Teses e Dissertações, durante o período entre 2014 e 2015, utilizando as seguintes palavras-chave e as correspondentes em inglês: audição, perda auditiva, ruído, fone de ouvido e combinações das mesmas.

Etapa 2: etapa aplicada onde tem-se o desenvolvimento por meio de análise das informações coletadas. Esta etapa é subdividida em 3 momentos, de acordo com o Guia de Orientação para o Desenvolvimento de Projetos (MERINO, 2014).

O GODP apresenta uma metodologia configurada por oito etapas que se fundamentam na coleta de informações pertinentes ao desenvolvimento da proposta, ao desenvolvimento criativo, a execução projetual, a viabilização e verificação final do produto. Estas etapas estão distribuídas em 3 momentos: 
Inspiração: Identificação da oportunidade, análise da problemática e levantamento de dados. Como parte do levantamento de dados, inclui-se o uso de técnicas de observação direta extensiva, neste caso por meio de questionário composto por perguntas abertas e de múltipla escolha (MARCONI, 2003). O mesmo foi disponibilizado online onde os respondentes o fizeram de forma voluntária.

Ideação: Organização e análise dos dados, geração de alternativas de projeto. Neste momento definem-se os requisitos de projeto, estes foram determinados de acordo com os fatores de risco identificados na revisão bibliográfica e desenvolvimento, e divididos em três blocos de informação (produto, usuário e contexto) de acordo com Merino (2014).

Implementação: Especificação e materialização, verificação e testes. Durante este momento realiza-se a avaliação do nível de pressão sonora do protótipo preliminar gerado a partir dos requisitos de projeto definidos. A avaliação foi aplicada no Laboratório de Vibração e Acústica da Universidade Federal de Santa Catarina, o profissional que auxiliou na aplicação foi o doutorando Júlio Alexandre Teixeira. O equipamento utilizado foi o HMS HEAD Measurement System Head Acoustics, instrumento que simula a audição humana. Os softwares que auxiliaram no processo foram: Head Acoustics Recorder, HMS III digital, Head Artemis 10.

\section{Fundamentação Teórica}

\subsection{Audição}

A audição é uma das principais capacidades sensoriais do ser humano, é a consciência da vibração interpretada como som. O ouvido humano possui como função converter a vibração física em um impulso nervoso, que é então interpretado pelo cérebro (ALBERTI).

A grande maioria dos jovens é exposto ao risco de perda auditiva utilizando fones de ouvido, sendo que uma porcentagem significante utiliza os dispositivos de maneira inapropriada (FLIGOR, 2010). Estudos atuais comprovam que o uso abusivo de dispositivos pessoais combinado aos fones de ouvido é muito difundido e será a causa de uma epidemia da chamada perda auditiva induzida pela música (MIHL) (VOGEL et al, 2008; FLIGOR, 2010; TORRE III, 2008; FIEDLER; KRAUSE, 2010).

Os níveis de saída do som dos dispositivos portáteis de áudio são suficientemente elevados para prejudicar a audição do utilizador, no entanto dependem ainda de variáveis como tempo de exposição, volume e o próprio fone de ouvido. Segundo estudos de Portnuff, Fligor e Arehart (2011), os hábitos de grande parte dos usuários são suficientes para causar a perda auditiva, e estes não possuem consciência destas consequências, o que dificulta a mudança de hábitos.

Nos Estados Unidos, o NIOSH (National Institute for Occupational Safety and Health) define como som prejudicial aquele que excede $85 \mathrm{~dB}$ em um turno de trabalho de 8 horas. No Brasil a NR 15 (1978), determina limites de tolerância do nível de ruído de acordo com a máxima exposição diária (Figura 2). 
Design para saúde e qualidade de vida: desenvolvimento e avaliação de requisitos de projeto para fone de ouvido inclusivo.

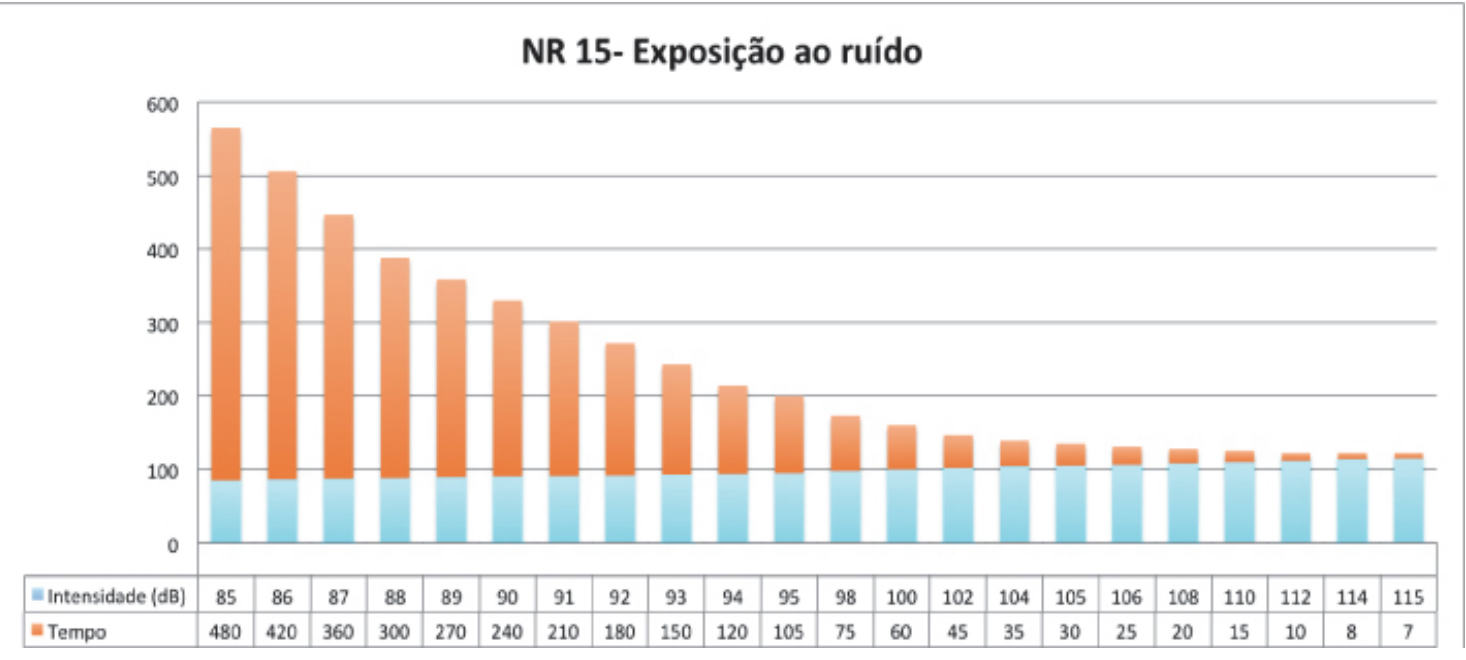

Fig. 35-Recomendações da NR 15 quanto exposição ao ruído

Em uma avaliação dos dispositivos pessoais de áudio mais populares realizada por Keith, Michaud e Chiu (2008), na configuração de volume máximo, o nível sonoro dos dispositivos atingiu uma faixa de 101 à $107 \mathrm{~dB}$. Considerando os hábitos comuns entre os jovens e a NR 15, verifica-se que, neste nível, o tempo de exposição máxima deveria ser de 20 minutos à 1 hora.

O mesmo estudo afirma que o nível sonoro pode chegar a $125 \mathrm{dBA}$, considerando as variáveis do fone de ouvido e da voltagem do dispositivo. De acordo com Liang et al (2012), tanto as condições do ambiente externo quanto o fone de ouvido podem influenciar o nívelsonoro dos dispositivos.

Uma grande parcela dos usuários jovens afirma ser consciente quanto aos malefícios de seu comportamento para sua audição, e afirmam que a responsabilidade pela proteção da mesma é da indústria (DANIEL, 2007; VOGEL et al, 2008; MCNEILL et al, 2010). Salientando o potencial do design para interferir no segmento, uma vez que este ao ser inserido no projeto, pode considerar os aspectos da interação humana com o produto, compreendendo as necessidades dos usuários e buscando satisfazê-las.

\section{$3.2 \mathrm{O}$ uso de fones de ouvido}

Os fones de ouvido em geral são dispositivos para reprodução individualizada do som. Este possui diferenciações quanto à forma, segundo a ITU (International Telecommunication Union, 2011), dividindo-se em, circumaural, supra-auricular, auricular e intra-auricular. Conforme ilustrado na figura a seguir (Figura 3). 


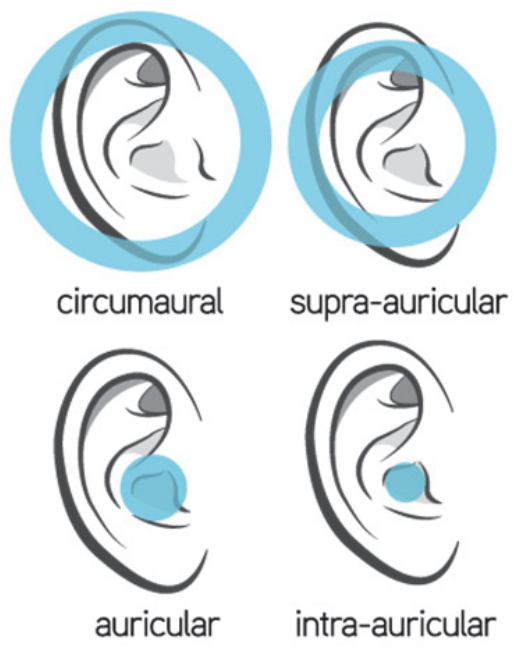

Fig. 3- Modelos de fones de ouvido.

Segundo Fligor e Cox (2004), a configuração de volume selecionada pelo usuário depende de diversos fatores, entre eles, o ruído do ambiente, as características do fone de ouvido utilizado e preferência do usuário quanto a razão ruído externo-intensidade sonora. Fones de ouvido que atenuam o ruído externo tendem a reduzir a configuração de volume selecionada pelo usuário (FLIGOR; COX, 2004).

Experimentos de Fligor e Ives (2006), demonstram também que o gênero é um fator influenciador, homens tendem à ouvir música em volume mais elevado que as mulheres.

Quanto à variável tempo de exposição, em uma pesquisa realizada em 2009 com 2500 sujeitos, 25\% afirmaram ouvir música com fones de ouvido por cerca de 15 horas semanais. Na mesma pesquisa, $75 \%$ dos sujeitos afirmaram utilizar earbuds (auriculares ou intra-auriculares), que costumam oferecer maior risco à audição do usuário (QUINTANILLA-DIECK; ARTUNDUAGA; EAVEY, 2009).

Em geral, fones de ouvido do tipo concha (circumaural e supra-auricular) possuem cancelamento de ruído passivo devido à suas propriedades formais. Para referência, estes modelos de fone de ouvido, em sua forma básica podem ser divididos em concha; posicionada sobre a orelha, onde o som é emitido; e arco, suporte que é posicionado na parte superior da cabeça (Figura 4).

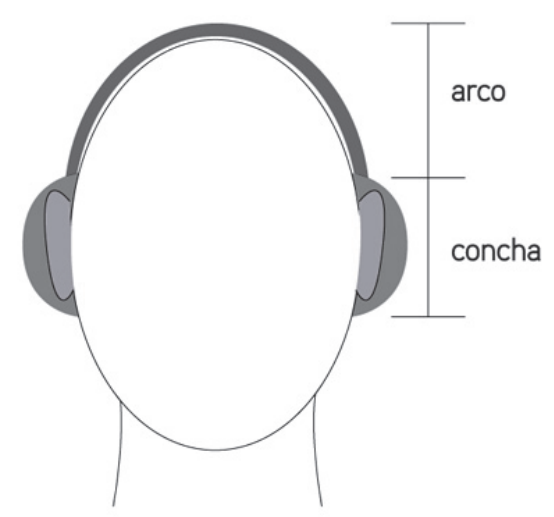

Fig. 4- Forma básica dos fones de ouvido tipo concha. 
Design para saúde e qualidade de vida: desenvolvimento e avaliação de requisitos de projeto para fone de ouvido inclusivo.

\subsection{Design, ergonomia e tecnologia assistiva}

O design por definição é o ato de projetar, independente da nomenclatura específica um projeto é para pessoas (DESIGN COUNCIL). Pessoas possuem diferentes habilidades, capacidades e necessidades.

A ergonomia como disciplina científica trata da interação entre o ser humano e demais elementos em um sistema (IEA, 2000). Esta, inserida na prática projetual, considera as variáveis desta relação; tais como antropometria, alcances, ambiente de interação, entre outras; buscando adequar o produto ao usuário, para que o output gerado dessa relação possa ser positivo.

O design, assim como a ergonomia, pode ser inserido no contexto das tecnologias assistivas atuais. A grande maioria dos produtos voltados para pessoas com deficiência no mercado atualmente, são projetados para serem camuflados durante o uso, gerando um princípio de exclusão social e colocando a deficiência como sujeito necessitado de camuflagem (PULLIN, 2009).

Esta característica de produto projetado para ser escondido pode ser exemplificada pela evolução dos aparelhos auditivos que se observa na figura 5. Além do tamanho, que diminuiu significativamente ao longo dos anos, as cores oferecidas tentam aproximar-se do tom de pele.

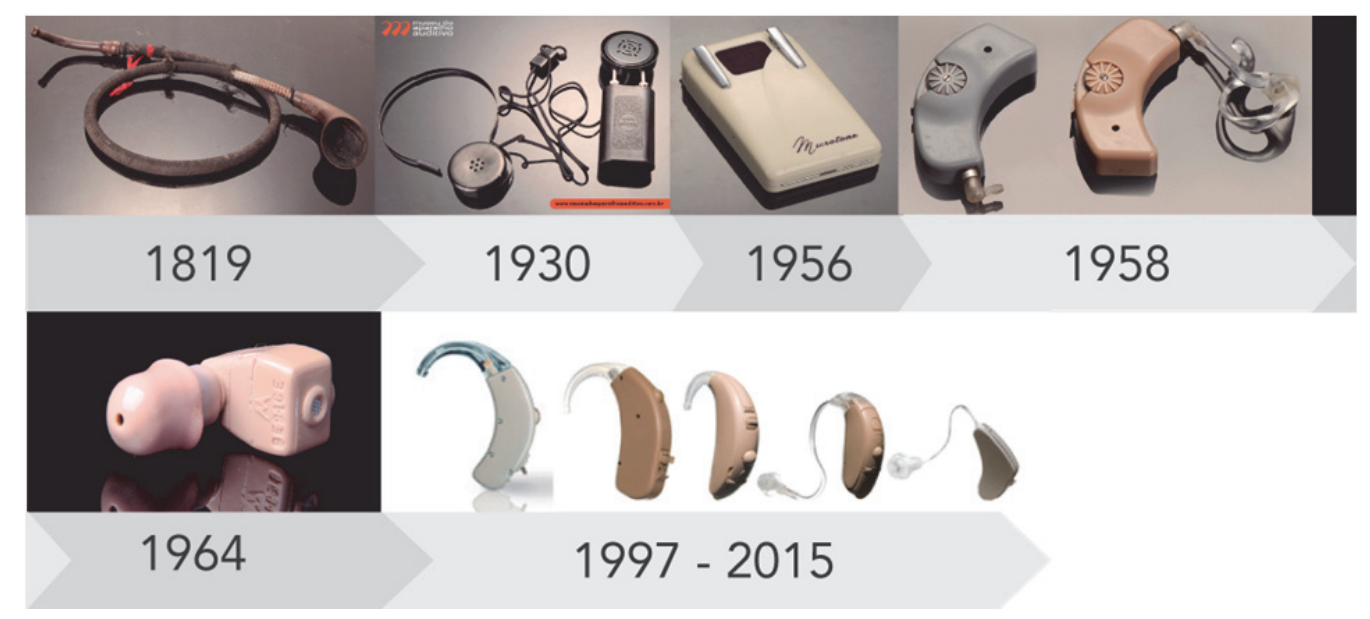

Fig. 5- Evolução dos aparelhos auditivos ${ }^{72}$. Fonte: <http://museudoaparelhoauditivo.com.br/>

Entende-se que o design e a ergonomia possuem potencial para o projeto de tecnologias assistivas que considerem, em primeiro lugar, o ser humano para o qual se está projetando, buscando como resultado produtos que promovam melhoria na saúde e bem-estar, consequentemente favorecendo a qualidade de vida dos usuários.

O design inclusivo, segundo Pereira (2009), dentro da prática projetual é o desenvolvimento de algo que possa ser utilizado por todos, a pensar num público específico com deficiências ou mobilidades reduzidas.

Partindo deste princípio, segundo o mesmo autor, o design inclusivo deve ser um imperativo social, uma necessidade de todos os cidadãos e um contributo para a igualdade de direitos. Imrie e Hall (2001) reforçam ainda a ideia de que ao design inclusivo pode também ser atribuída a responsabilidade de

\footnotetext{
${ }^{72}$ Para fins de exemplificação, os modelos apresentados são aparelhos auditivos retroauriculares
} 
promover o desenvolvimento de sociedades mais tolerantes, cooperantes e equilibradas, respeitadoras do conceito dos direitos humanos.

A privação de qualquer pessoa de um hábito, ou uso de qualquer produto devido à uma deficiência afeta diretamente sua relação com a sociedade. Quando refere-se às crianças a exclusão pode afetar diretamente seu desenvolvimento. Como ressaltam Rui e Steffani, a respeito da relação da musica com o desenvolvimento infantil:

“A música faz parte do dia a dia de todas as pessoas desde a mais tenra idade. È aliada importante especialmente na educação infantil, pois através da vivência musical procura-se desenvolver habilidades diversas nas crianças e, ao mesmo tempo, promover a sociabilidade no grupo" (RUI; STEFFANI)

A adequação do fone de ouvido dimensionado para possibilitar o uso com o aparelho auditivo, promove a inclusão e reflete diretamente no bem estar dos usuários, independentemente da deficiência.

Importante pontuar que, considera-se o modelo de aparelho auditivo com as maiores dimensões, para que assim, ao adequar o fone de ouvido ao mesmo, os demais modelos sejam atendidos. Sendo este o modelo BTE ou retroauricular.

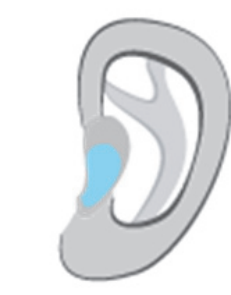

Micro canal

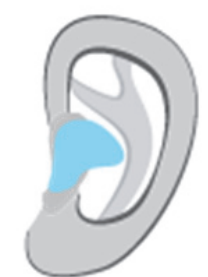

Intracanal

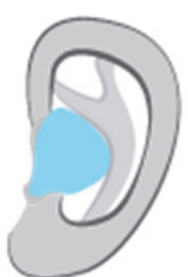

Intra auricular

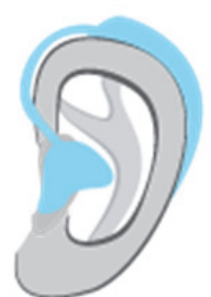

Retroauricular

Fig. 6- Ilustração dos quatro principais modelos de aparelho auditivo 
Design para saúde e qualidade de vida: desenvolvimento e avaliação de requisitos de projeto para fone de ouvido inclusivo.

\subsection{Síntese da Fundamentação Teórica}

Apresenta-se na imagem a seguir, em formato de infográfico, a síntese da fundamentação teórica (Figura 7).
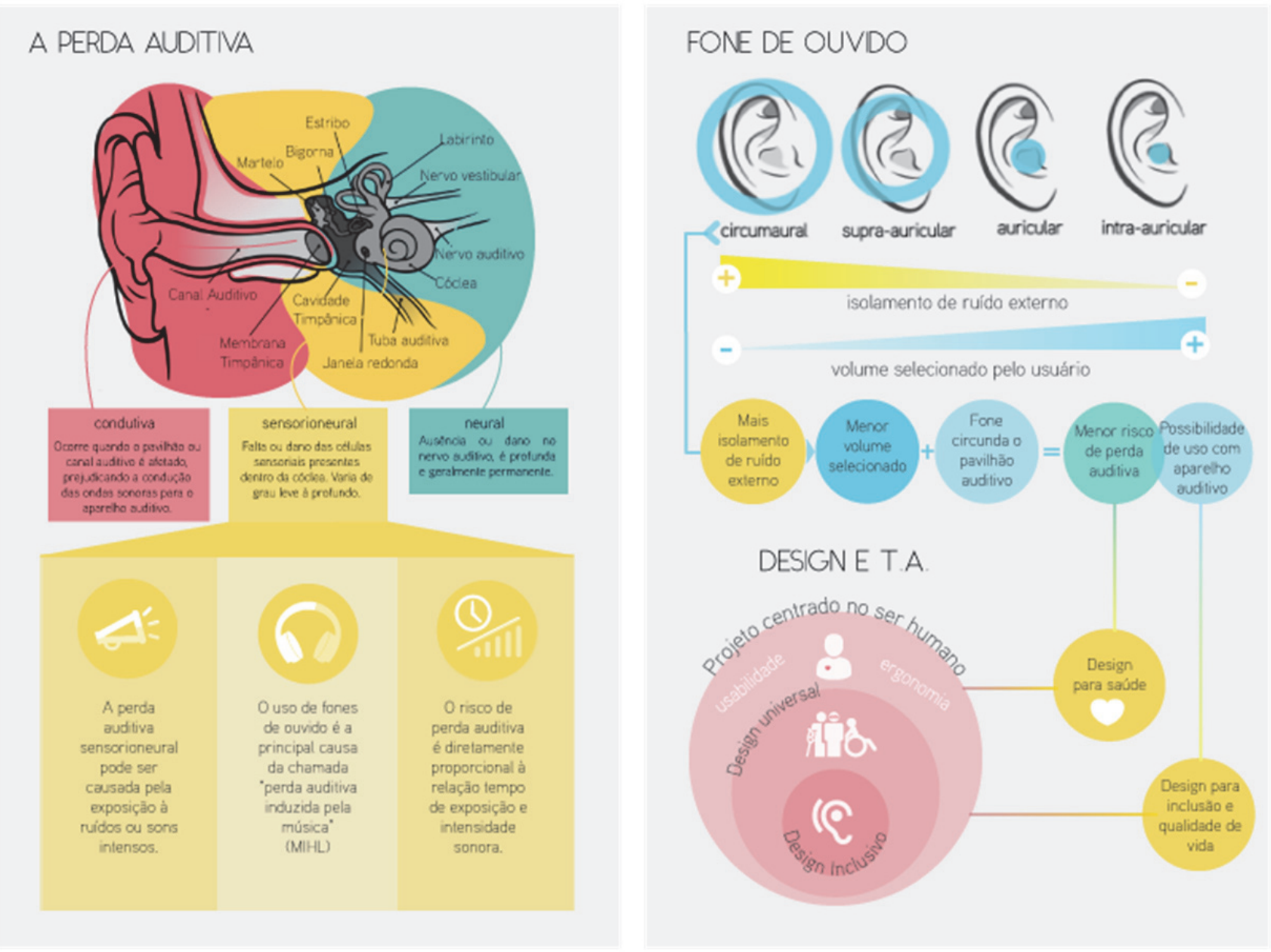

\section{Pesquisa Aplicada}

\subsection{Inspiração}

A oportunidade de projeto surgiu da observação da dificuldade de usuários de aparelho auditivo possuem em usar fones de ouvido. Observou-se que para utilizar fones auriculares ou intra-auriculares é necessário retirar o aparelho auditivo o que pode acabar prejudicando ainda mais a audição do usuário, uma vez que sem o aparelho auditivo a configuração de volume selecionada pelo usuário tende a ser ainda mais elevada, por outro lado, fones circumaurais ou supra-auriculares podem causar desconforto por não possuírem dimensões compatíveis para uso simultâneo com o aparelho. 
Concomitantemente, constatou-se que o fone de ouvido pode causar perda auditiva quando combinados alguns fatores de risco, assim como apresentado na fundamentação teórica.

O design atua nos dois argumentos, buscando como resultado um produto voltado para a inclusão dos usuários de aparelho auditivo e a proteção da audição de usuários de fone de ouvido.

Assim durante a etapa de inspiração, buscam-se informações sobre o ser humano para o qual se está projetando, por meio de pesquisa de campo e síntese das informações coletadas.

\subsubsection{Pesquisa de Campo}

Para identificar os usuários e consequentemente, características do fone de ouvido a serem melhoradas, realizou-se uma observação direta extensiva, por meio de questionário.

Direcionaram-se as perguntas do questionário para os hábitos dos usuários ao ouvir música utilizando fones, sua consciência com relação à perda auditiva, com perguntas abertas e fechadas de múltipla escolha. Também questões que definem o perfil do usuário. Em um primeiro momento o questionário é direcionado a relação entre produto, usuário e contexto, apresentadas sob a forma de gráficos nas imagens a seguir (Figuras 8 e 9). 
Design para saúde e qualidade de vida: desenvolvimento e avaliação de requisitos de projeto para fone de ouvido inclusivo.

Masculino

Feminino

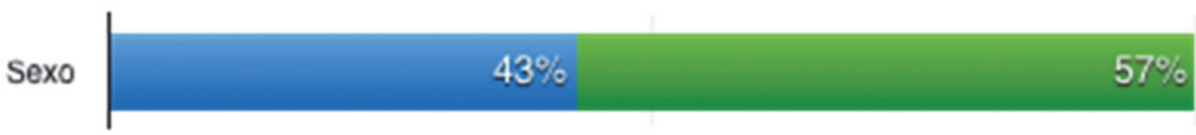

Você possui alguma deficiência? Se sim, qual?

\begin{tabular}{|l|l|}
$\begin{array}{l}\text { Nao possuo } \\
\text { Auditiva }\end{array}$ & $\begin{array}{l}\text { Visual } \\
\text { Outro }\end{array}$ \\
\hline & $74 \%$ \\
\hline $22 \%$ \\
\hline $6 \%$ \\
\hline$\%$
\end{tabular}

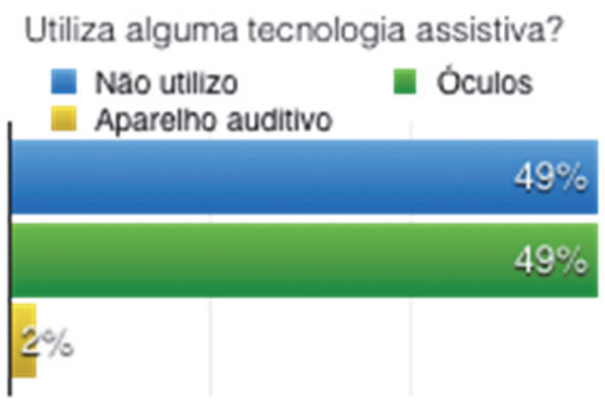

Você considera a configuração de volume que utiliza:

Onde você costuma utilizar fones de ouvido?
Baixo Moderado
Alto Extremamente alto

60
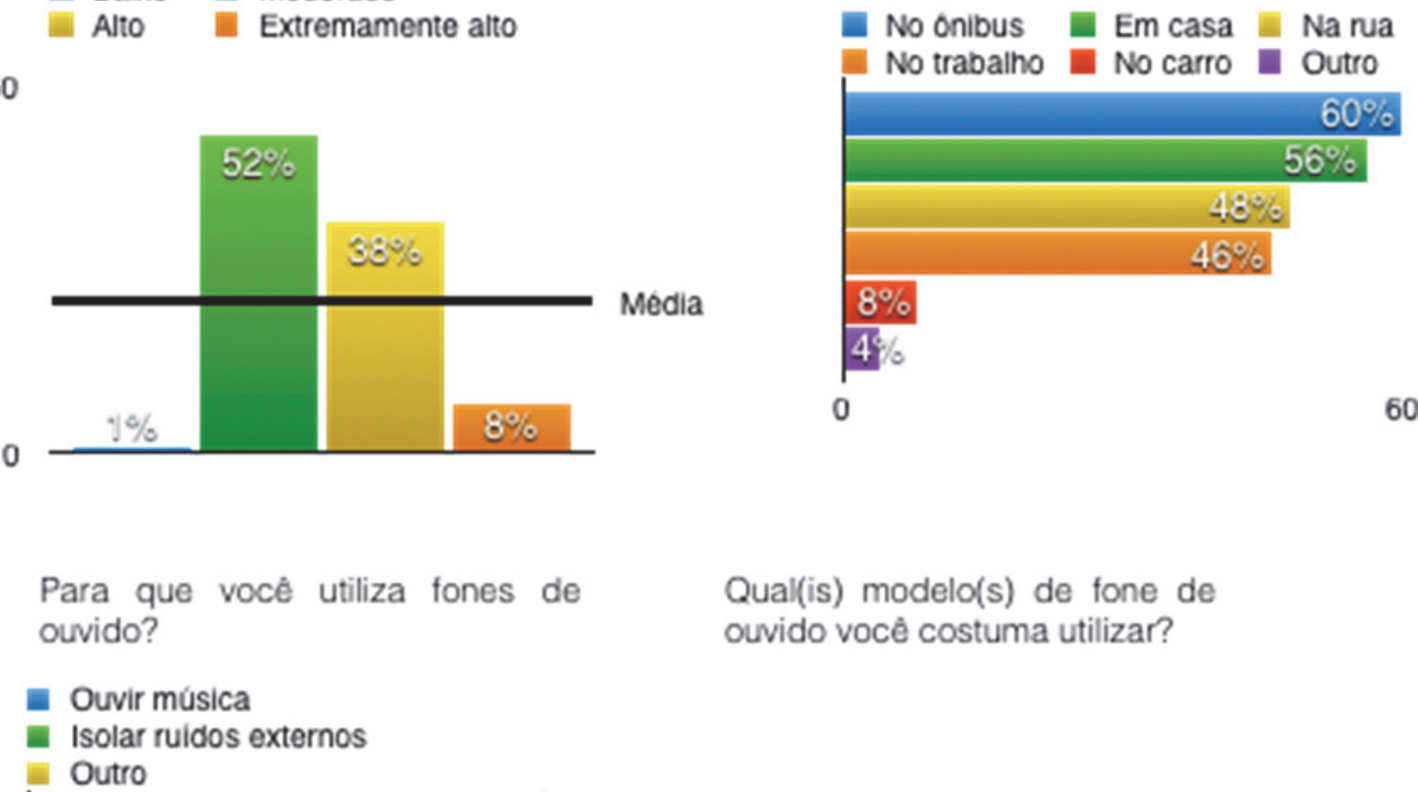

Fig. 8- Gráficos resultantes dos questionários aplicados 


\section{Qual(is) modelo(s) de fone de ouvido você costuma utilizar?}

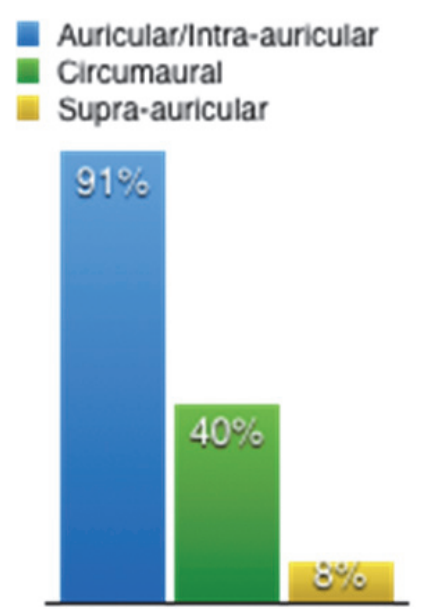

\section{Por quanto tempo você utiliza fones de ouvido diariamente?}
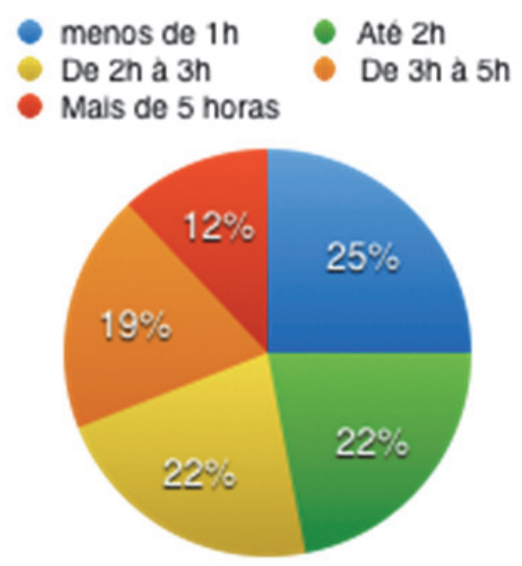

Fig. 9- Gráficos resultantes dos questionários aplicados

Em um segundo momento, as questões abertas são relacionadas aos hábitos dos usuários.

Quando perguntados sobre qualquer conhecimento ou preocupação relacionada ao risco do uso de fones de ouvido para audição, cerca de $80 \%$ dos respondentes afirmam possuir consciência quanto ao risco do uso de fone de ouvido para a audição, destes, $21 \%$ afirmam que não tem cuidado nenhum e não possuir pretensão de mudar os hábitos ainda que possa ter sua audição prejudicada.

Além das características citadas relacionadas ao som, 37\% salientaram o desconforto ou dor devido ao contato do fone com a orelha, e 38\% citaram o incômodo quanto ao fato dos fios ficarem "enosados". Os respondentes citaram também a impossibilidade ou desconforto de uso simultâneo com os óculos, sendo que $49 \%$ dos respondentes os utilizavam.

Com base nas informações levantadas na etapa de inspiração foi possível determinar o modelo do fone de ouvido a ser projetado, sendo este o circumaural, que circunda o pavilhão auditivo, em razão das características pontuadas:

-cancelamento de ruído passivo;

-tendência do usuário de selecionar uma configuração de volume menor, se comparado aos demais modelos;

-possibilidade de adaptação ao uso simultâneo com aparelho auditivo

\subsection{Ideação}

$\mathrm{Na}$ etapa de ideação, as informações coletadas foram analisadas para a geração dos requisitos de projeto e consequentemente a geração de alternativas. 
Design para saúde e qualidade de vida: desenvolvimento e avaliação de requisitos de projeto para fone de ouvido inclusivo.

Assim, destaca-se a escala de influência das variáveis de risco pontuadas durante o levantamento de dados, na figura a seguir (Figura 10).

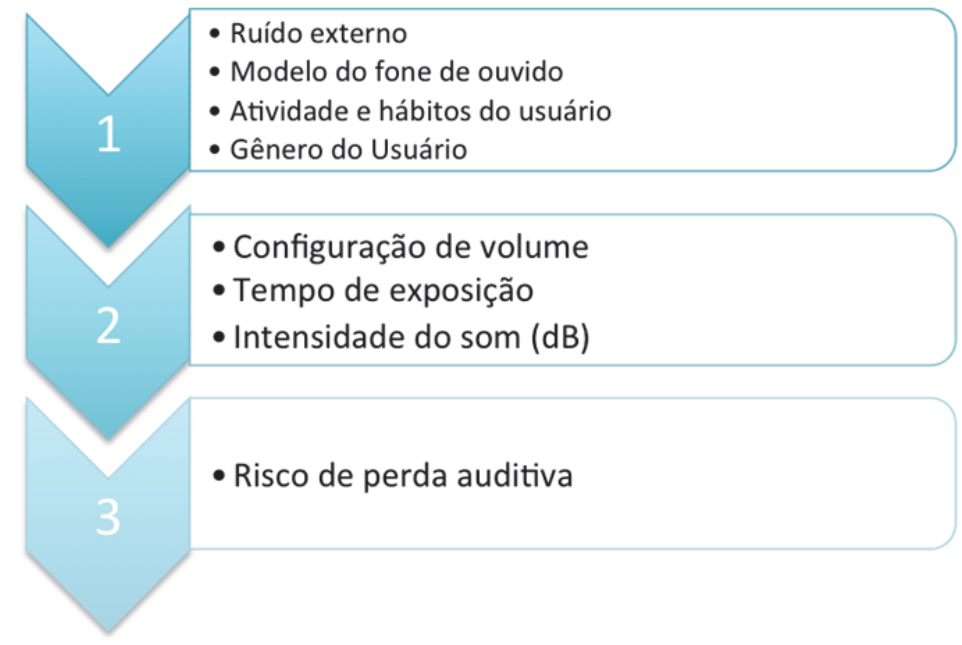

Fig. 10- Influência das variáveis no risco de perda auditiva.

Também com base nas informações apresentadas, analisa-se o perfil do usuário extremo apresentado na Figura 11, este representa o usuário que tem a sua audição exposta à um risco extremamente alto, devido aos seus hábitos e características, considerando também os usuários de aparelho auditivo. 


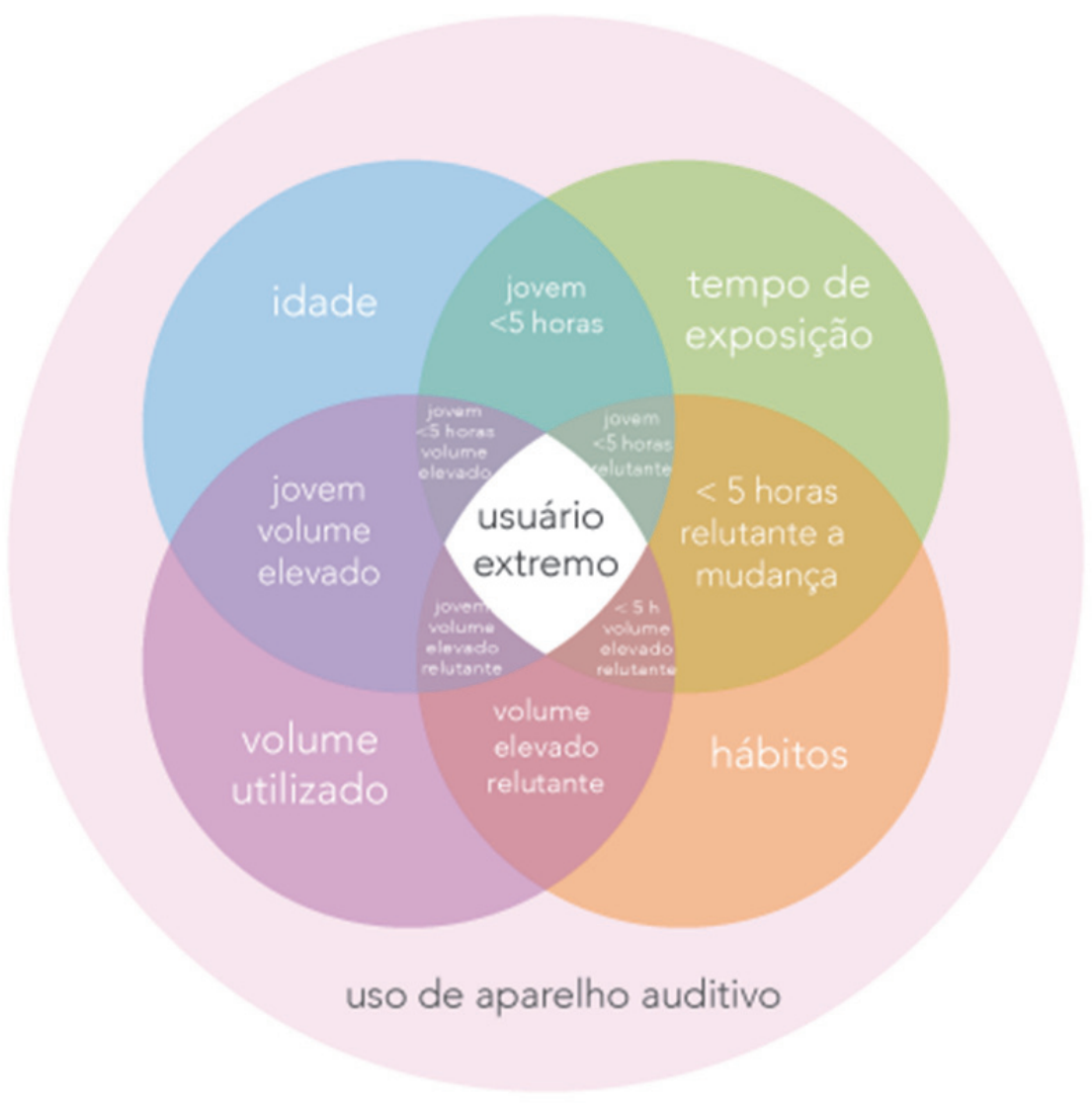

Fig. 11- Representação de intersecção de conjuntos referente às variáveis de risco

Quanto às características e hábitos do usuário extremo justificam-se:

- O tempo elevado de exposição aumenta o risco de perda auditiva;

-O usuário que não tem pretensão de mudar os hábitos depende de influências ou controles externos para proteger sua audição;

-A configuração de volume selecionada afeta diretamente o risco de perda auditiva;

-Jovens tendem a utilizar fones de ouvido com maior frequência;

\subsubsection{Requisitos}

Constata-se que, um produto que previna ou diminua o risco da perda auditiva independente dos hábitos dos usuários, é mais eficaz do que a conscientização dos riscos, uma vez que ainda consciente o usuário demonstra relutância quando a mudança de comportamento. Reforçando o princípio ergonômico de adaptar o produto ao usuário.

Um produto centrado no usuário deve considerar as possíveis condições de uso, relacionadas às capacidades do usuário e sua interação com o produto, assim como o contexto em que está inserido (Tabela 1). 
Design para saúde e qualidade de vida: desenvolvimento e avaliação de requisitos de projeto para fone de ouvido inclusivo.

Tabela 1- Requisitos de projeto segmentados nos blocos de informação

\begin{tabular}{|c|c|c|}
\hline PRODUTO & USUÁRIO & CONTEXTO \\
\hline Limitar a intensidade sonora: $<85 \mathrm{~dB}$ & $\begin{array}{l}\text { Proteger a audição independente das } \\
\text { configurações escolhidas. }\end{array}$ & $\begin{array}{l}\text { Cancelamento do ruido externo passivo } \\
\text { (baixo custo) }\end{array}$ \\
\hline $\begin{array}{l}\text { Isolamento acústico: } \\
\text { Interno->externo } \\
\text { Externo->interno }\end{array}$ & $\begin{array}{l}\text { Arco regulável: } \\
\text { (percentil } 5 \text { mulher- } 95 \text { homem): } \\
\text { comprimento do arco } 300-371 \mathrm{~mm}\end{array}$ & $\begin{array}{l}\text { Borracha do arco antiderrapante para } \\
\text { atividades com movimento }\end{array}$ \\
\hline $\begin{array}{l}\text { Formato interior da concha: } \\
\text { côncavo }\end{array}$ & $\begin{array}{l}\text { Permitir uso simultâneo com aparelho } \\
\text { auditivo: } \\
\text { Dimensões internas da concha: } \\
60 \times 70 \mathrm{~mm} \\
\text { Dimensões externas: } \\
70 \times 80 \mathrm{~mm}\end{array}$ & $\begin{array}{l}\text { Ventilação nas partes de contato devido } \\
\text { à transpiração. }\end{array}$ \\
\hline $\begin{array}{l}\text { Estrutura dobrável, para ocupar menos } \\
\text { espaço quando guardado. }\end{array}$ & $\begin{array}{l}\text { Uso simples e intuitivo eliminando } \\
\text { estruturas desnecessárias }\end{array}$ & \\
\hline $\begin{array}{l}\text { Suporte para enrolar os fios, } \\
\text { Evitando nós. }\end{array}$ & $\begin{array}{l}\text { Confortável: } \\
\text { Arco e concha almofadados nos } \\
\text { contatos com o usuário. }\end{array}$ & \\
\hline $\begin{array}{l}\text { Baixo custo: } \\
\text { Estrutura simplificada, } \\
\text { Minima variedade de materiais }\end{array}$ & $\begin{array}{l}\text { Acomodar óculos (permitir uso } \\
\text { simultâneo. }\end{array}$ & \\
\hline
\end{tabular}

\subsubsection{Geração de alternativas}

Considerando o objetivo de desenvolvimento de um produto que reduza os riscos à saúde do usuário, prevenindo danos ao sistema auditivo, o produto se sustenta na conversão dos modelos intra-auriculares $\backslash$ auriculares para o circumaural, permitindo ao usuário utilizar simultaneamente ao aparelho auditivo, devido as dimensões da concha, além de limitar a intensidade sonora do som e consequentemente interferindo diretamente na diminuição do risco de perda auditiva durante a utilização do fone (Figura 12 e 13). 


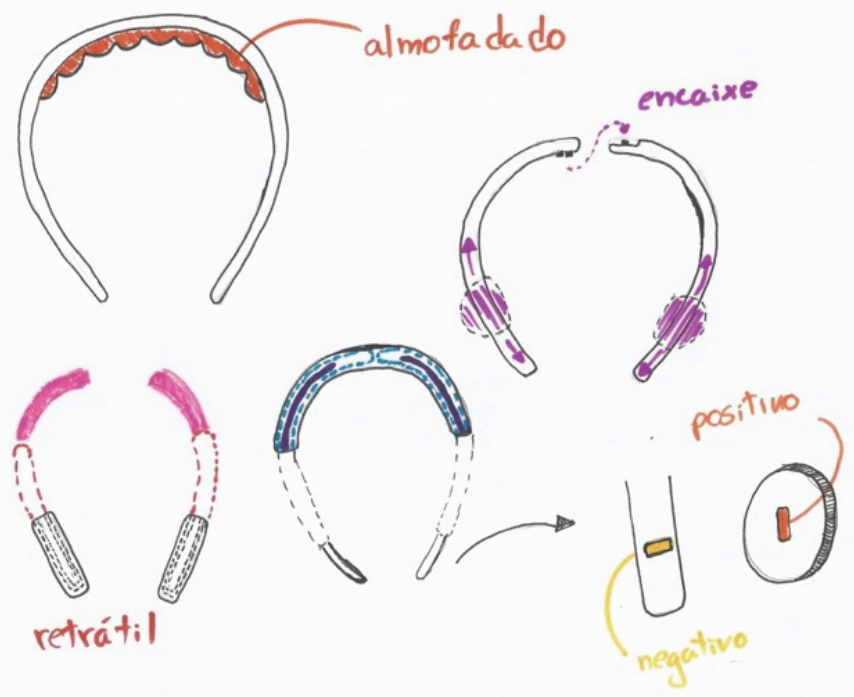

Fig. 12- Esboços de alternativas para o arco e concha
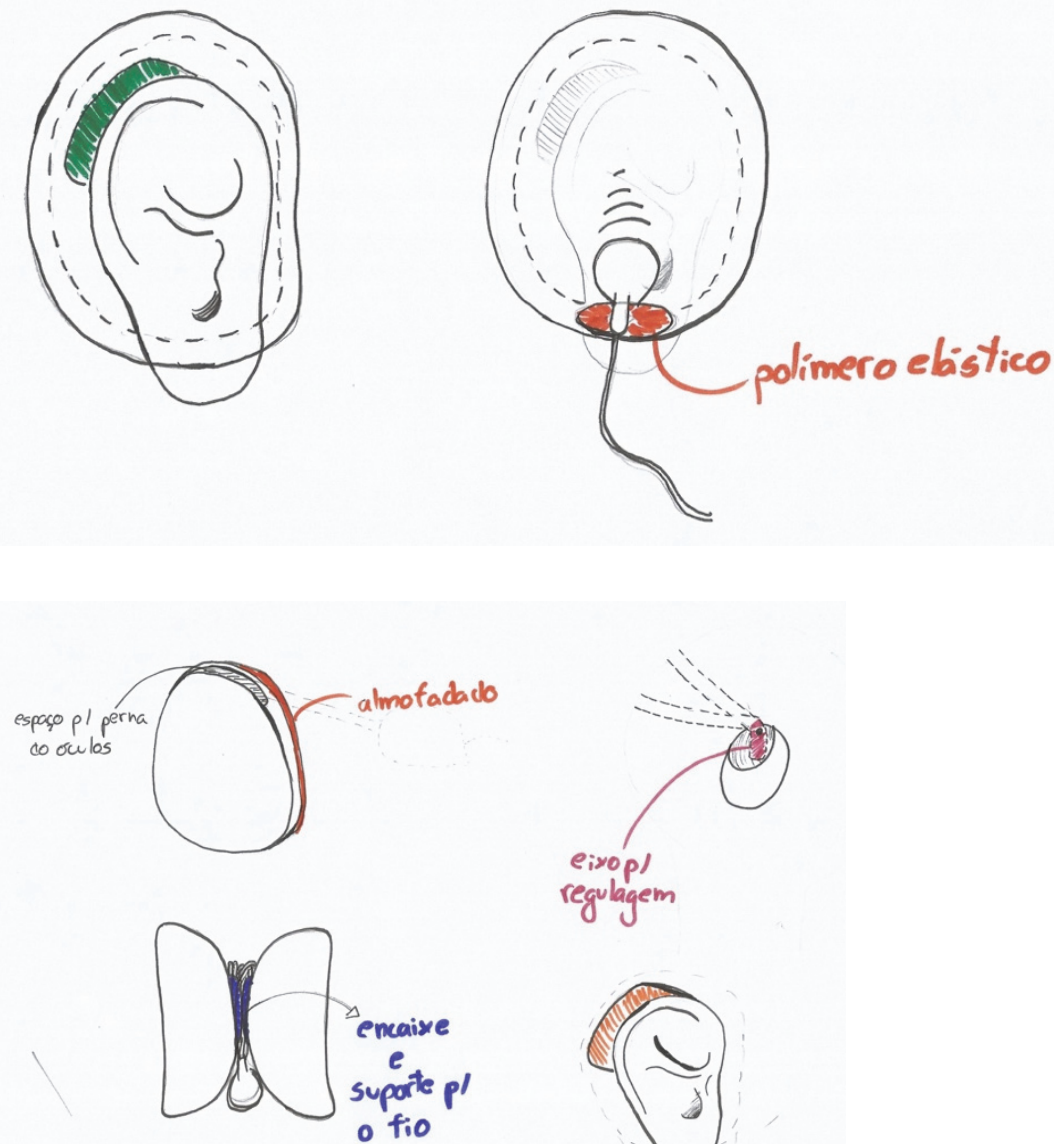

regulagem

Fig. 13- Desenho esquemático do funcionamento 
Design para saúde e qualidade de vida: desenvolvimento e avaliação de requisitos de projeto para fone de ouvido inclusivo.

Assim, apresenta-se na figura seguir o modelo 3D da alternativa final selecionada com base nos requisitos de projeto definidos (Figura 14).

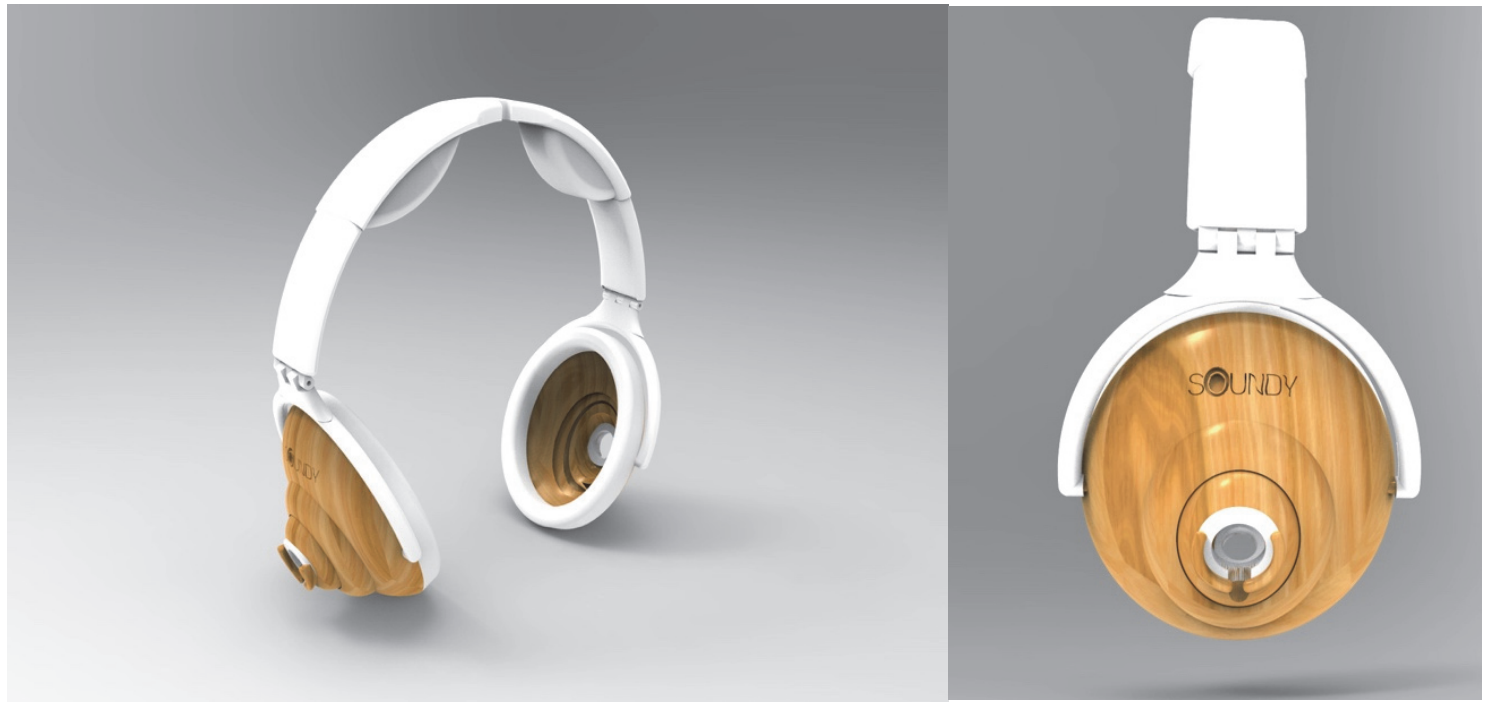

Fig. 14- Modelo 3D da alternativa final

\subsection{Implementação}

\subsubsection{Protótipo}

Para a realização da simulação com o fone de ouvido projetado a partir dos requisitos anteriormente apresentados, gerou-se um protótipo preliminar da concha, para o mesmo utilizou-se do dimensionamento definido.

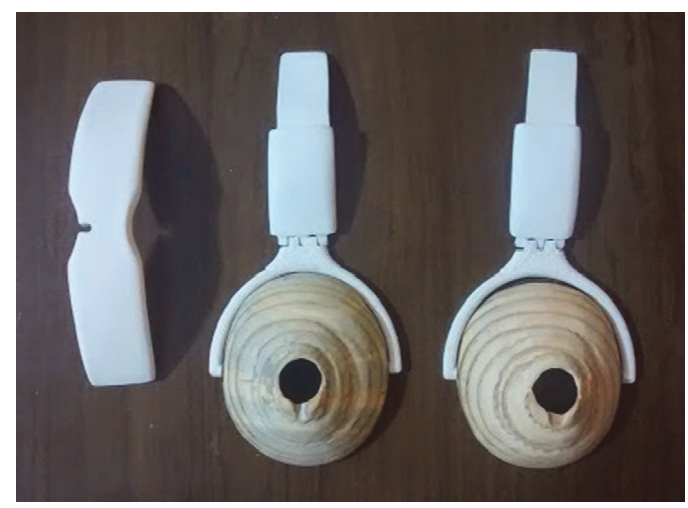

Fig. 15- Protótipo da alternativa final

\subsubsection{Avaliação do nível de pressão sonora}

Como parte do processo, realizou-se um teste piloto onde foi avaliada a intensidade máxima do som atingida em $\mathrm{dB}$ com o fone de ouvido projetado a partir dos requisitos definidos. Esta tem como objetivo certificar a não agressão à saúde auditiva do usuário do dispositivo.

A avaliação foi aplicada no Laboratório de Vibração e Acústica da Universidade Federal de Santa Catarina, o profissional que auxiliou na aplicação foi o doutorando Júlio Alexandre Teixeira.

Os procedimentos do teste foram: 
- Fixação do Amplificador para fones intra-auriculares no equipamento HMS HEAD Measurement System Head Acoustics;

- Reprodução de tons puros em 8 frequências distintas $(100,200,500,1000,2000,5000,10000$, $12000 \mathrm{~Hz})$

- Reprodução de ruído branco ${ }^{73}$;

- Gravação dos sons captados pela Head Acoustics;

- Medição em dB do som captado com o software HMS III digital;

- Avaliação dos resultados com o software Head Artemis 10.

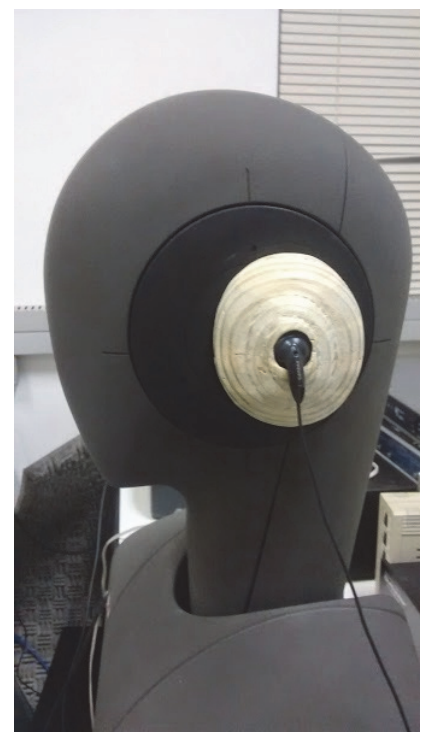

Fig. 16- Avaliação do nivel de pressão sonora

Nos tons puros os resultados alcançados apresentam-se na tabela a seguir (Tabela 2).

Tabela 2- Níveis de pressão sonora atingidos

\begin{tabular}{|l|l|l|}
\hline Sinal & dB & dBA \\
\hline $\mathbf{1 0 0}$ & 79,92 & 64,55 \\
\hline $\mathbf{2 0 0}$ & 91,27 & 80,65 \\
\hline $\mathbf{5 0 0}$ & 93,41 & 90,16 \\
\hline $\mathbf{1 0 0 0}$ & 96,92 & 96,92 \\
\hline $\mathbf{2 0 0 0}$ & 86,3 & 87,54 \\
\hline $\mathbf{5 0 0 0}$ & 92,23 & 93,11 \\
\hline $\mathbf{1 0 0 0 0}$ & 93,88 & 92,14 \\
\hline $\mathbf{1 2 0 0 0}$ & 92,33 & 89,1 \\
\hline
\end{tabular}

${ }^{73}$ Combinação simultânea de sons de todas as frequências. 
Design para saúde e qualidade de vida: desenvolvimento e avaliação de requisitos de projeto para fone de ouvido inclusivo.

Neste estudo utiliza-se o dB SPL (decibel nível de pressão sonora), e dBa, a intensidade do som filtrada, sendo esta relativa às diferentes frequências. Considera-se nesse estudo o $\mathrm{dBa}$, pois adequa-se melhor ao objetivo proposto. Este definido por Fernandes (2002):

"É a quantidades em dB medida com o medidor de nível sonoro com a incorporação de um filtro de freqüências. A curva $\mathrm{A}[\mathrm{dB}(\mathrm{A})]$ é muito próxima da resposta subjetiva, sendo usada em medições de níveis de ruído e perda de audição induzida por ruído. “ (FERNANDES, 2002)

Os resultados da reprodução de ruído branco foram convertidos graficamente, considerando o nível de pressão sonora em dB em função da frequência em Hz.

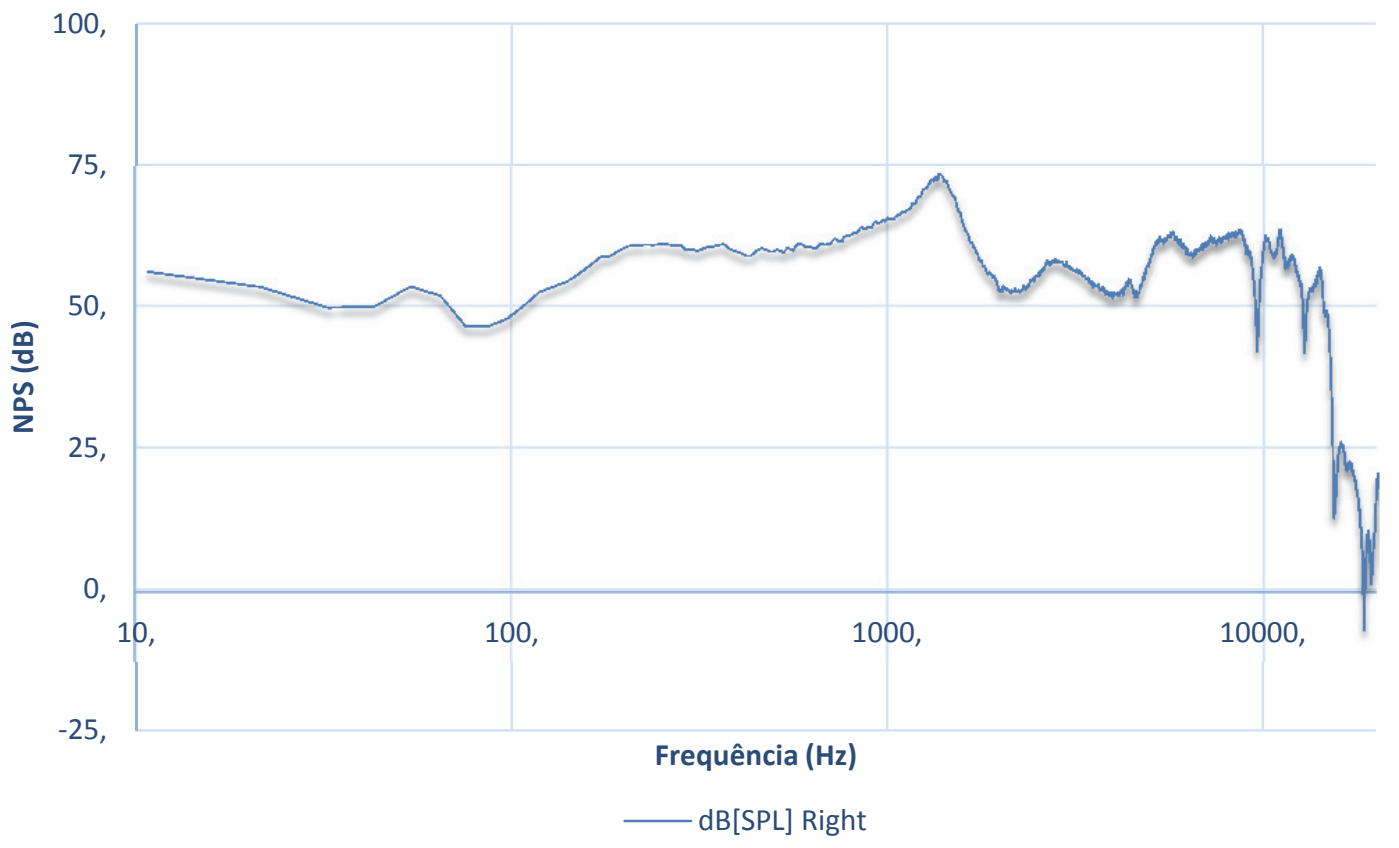

Fig. 17- Gráfico do nivel de pressão sonora em dB em função da frequência em $\mathrm{Hz}$.

Observa-se que entre as frequências de $1300 \mathrm{~Hz}-1400 \mathrm{~Hz}$ ocorre o máximo nível de pressão sonora, $73 \mathrm{~dB}$. Considerando que as músicas em geral não ultrapassam os $5000 \mathrm{~Hz}$.

Considerando os tons puros, o nível de pressão sonora atingiu seu maior valor na frequência $1000 \mathrm{~Hz}$, sendo 96,92 dBa. Nessa intensidade o tempo de exposição recomendado é de 1 hora e 45 minutos.

Considerando o ruído branco, os resultados foram considerados satisfatórios, umas vez que $73 \mathrm{~dB}$ está abaixo do limite recomendado pela literatura, a proteção auditiva é recomendada apenas acima de $85 \mathrm{~dB}$. Ressaltando que seria desejável um valor menor na avaliação com tons puros, no entanto, ainda considerando o valor atingido de $96,92 \mathrm{dBa}$, este é menor que os fones de ouvido atualmente no mercado.

Assim, sinteticamente apresenta-se na imagem a seguir as principais características estruturais do produto resultante. 


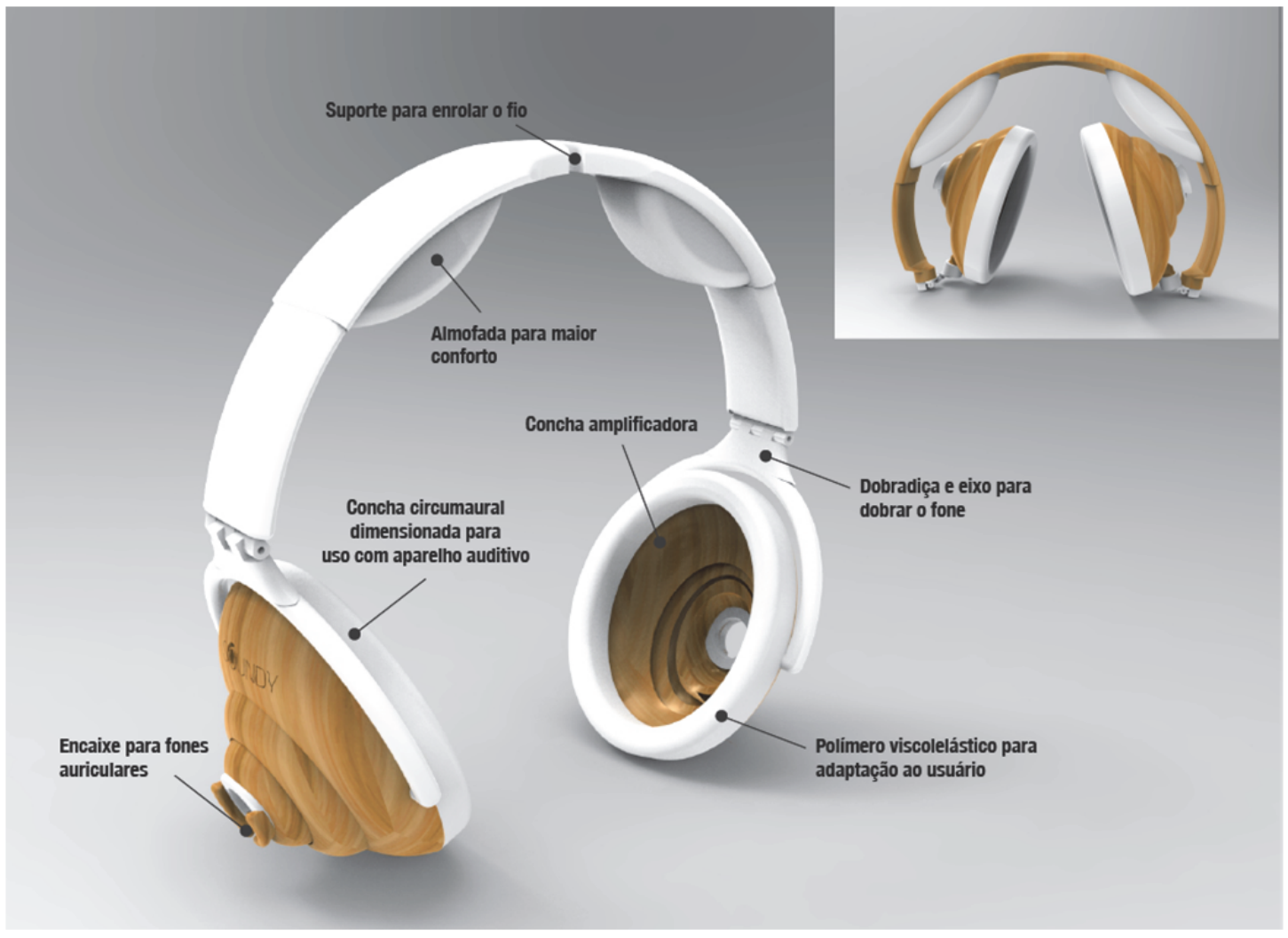

Fig. 18-Características estruturais do produto final

\section{Conclusões}

O resultado da avaliação do nível de pressão sonora permitiu verificar a viabilidade da pesquisa e a emprego dos requisitos gerados por meio da aplicação do design voltado à saúde auditiva. Destaca-se a problemática encontrada a partir do levantamento, sendo os hábitos dos usuários um fator de extrema relevância para a prevenção da perda auditiva causada pelo uso de fones de ouvido. Acrescendo à importância de um produto que independa dos hábitos, características e capacidades dos usuários para o funcionamento eficaz.

A pesquisa apresenta o potencial da interferência do design para a saúde, podendo contribuir com o bemestar e a qualidade de vida dos indivíduos. Considerando os benefícios da prevenção da perda auditiva, se eficaz pode evitar o uso de tecnologias assistivas, além de reduzir significativamente os custos.

O desenvolvimento de projetos centrados no usuário permite obter como resultados produtos voltados à atender as reais necessidades das pessoas considerando suas individualidades, capacidades e habilidades $\mathrm{e}$ permitindo a inclusão, especificamente neste estudo, de deficientes auditivos caracterizando-se como uma oportunidade para aplicação do design com o objetivo de integração dos indivíduos independentemente de suas restrições. O emprego adequado da ergonomia como ferramenta projetual contribui profundamente para a compreensão da maior parcela de potenciais usuários de um produto. $\mathrm{O}$ desenvolvimento de pesquisas voltadas a este intento é de extrema importância para o bem-estar dos usuários na relação com os produtos.

Os requisitos gerados podem nortear o desenvolvimento de produtos que tenham como objetivo a prevenção da perda auditiva induzida pela música e possibilitar a utilização de fones de ouvido por 
Design para saúde e qualidade de vida: desenvolvimento e avaliação de requisitos de projeto para fone de ouvido inclusivo.

usuários de aparelho auditivo. Considerando todos os aspectos mencionados e destacando a necessidade de posicionar o usuário como centro do projeto.

Como próximas etapas da pesquisa podem ser pontuados:

- Aprimoramento do protótipo com base nos requisitos gerados;

- Nova avaliação de nível de pressão sonora;

- Avaliação da adequação do fone de ouvido aos usuários de aparelho auditivo.

Finalmente, é possível concluir que existem oportunidades para o desenvolvimento e aprimoramento de produtos com base nesta pesquisa e resultados, buscando a proteção da audição dos usuários de fone de ouvido.

\section{Referências}

ALBERTI, P. W. (2015) “The anatomy and physiology of the ear and hearing”. In: GOELZER, Berenice; HANSEN, Colin H.; SEHRNDT, Gustav A. (Ed.). Occupational exposure to noise: evaluation, prevention and control. World Health Organization, ano desconhecido. Cap. 2. p. 53-62.

BRASIL. SUBSECRETARIA NACIONAL DE PROMOÇÃO DOS DIREITOS DA PESSOA COM DEFICIÊNCIA. (2009) Comitê de Ajudas Técnicas. Tecnologia Assistiva. - Brasília: CORDE.

DESIGN COUNCIL. What is design. Disponível em:

$<$ http://www.mech.hku.hk/bse/interdisciplinary/what_is_design.pdf $>$ Acesso em 03 de Janeiro de

FERNANDES, J. C. (2002 ) “Capítulo 6”. In: FERNANDES, João Candido. Bio-engenharia Aplicada aos Distúrbios da Comunicação Humana: Apostila desenvolvida para a disciplina. Bauru: Curso de Pós-graduação em Fonoaudiologia,. p. 10. UNESP Bauru.

FIEDLER, D. \& KRAUSE, R. (2010) "Deafness, Hearing Loss and the Auditory System”. Nova Science Publishers, Inc.,. $411 \mathrm{pp}$.

FLIGOR, B. J. \&; COX, L. C. (2004). "Output Levels of Commercially Available Portable Compact Disc Players and the Potential Risk to Hearing." Ear \& Hearing, 25 (6), p. 513-527.

FLIGOR, B. J \& IVES, T. E. (2006 ) "Does Earphone Type Affect Risk for Recreational Noise-induced Hearing Loss? Etymotic Research Inc. In: NIHL in Children Meeting, Cincinnati, OH. 2 p.

FLIGOR, B. (2010) "Recreational noise". In: CHASIN, Marshall. Hearing Loss and Noise. Arizona: Auricle Ink Publishing,

GIL, A. C. (2002) Como elaborar projetos de pesquisa. 4. ed. São Paulo: Atlas.

HAINES, N. C. et al. (2011) “Listening levels of teenage iPod users: does measurement approach matter?” Audilogy Research, 2 (6), p. 25-29.

HODGETTS, W. E; RIEGER, J. M; SZARKO, R. A. (2007 ) “The Effects of Listening Environment and Earphone Style on Preferred Listening Levels of Normal Hearing Adults Using an MP3 Player". Ear \& Hearing, 28 (3), p. 290-297.

IBGE. (2010) Censo Demográfico: Características gerais da população, religião e pessoas com deficiência. Rio de Janeiro: Ministério do Planejamento, Orçamento e Gestão. 215 p.

IEA- (2000) International Ergonomics Association. "Definição Internacional de Ergonomia.” San Diego, USA

IMRIE, R \& HALL, P. (2001) “An Exploration of Disability and the Development Process.” Urban Studies, v. 38, n. 2, p.333-350. 
ITU (2011) International Telecommunication Union. "Series P: Terminals and Subjective and Objective Assesment Methods. Objective Measuring Apparatus: Artifical Ears”. Telecommunication Standardization Sector Of Itu.

ISO (2014) International Organization for Standardization. Disponível em: <http://www.iso.org> . Acesso em: 22 out.

KEITH, S. E., MICHAUD, D. S., \& CHIU, V. (2008). "Evaluating the maximum playback sound levels from portable digital audio devices," J. Acoust. Soc. Am. 123, 4227-4237.

KIM, Myung Gu et al. (2009) "Hearing Threshold of Korean Adolescents Associated with the Use of Personal Music Players". Yonsei Medical Journal, 50 (6), p. 771-776, Dez.

LEVEY, S.; LEVEY, T. \& FLIGOR, B. J. (2011 ) "Noise Exposure Estimates of Urban MP3 Player Users.” Journal of Speech, Language and Hearing Research, 54, p. 263-277, Fev.

LIANG, M et al. (2012) "Characteristics of noise-canceling headphones to reduce the hearing hazard for MP3 users”. Acoustical Society of America, 131 (6), p. 4526-4536, Jun..

MAIA, F.; NIEMEYER, L. \& FREITAS, S. (2010) "A relação entre indivíduos com deficiência, suas emoções e o design de objetos de Tecnologia Assistiva”. In: CONGRESSO BRASILEIRO DE PESQUISA E DESENVOLVIMENTO EM DESIGN, 9., 2010, São Paulo. Anais. São Paulo: Blücher e Universidade Anhembi Morumbi. p. 1865.

MARCONI, M. de A. \& LAKATOS, E. M. (2003) Fundamentos de metodologia científica. 5. ed. São Paulo : Atla.

MCNEILL, K. et al. (2010) "MP3 player listening habits of 17 to 23 year old university students". Journal Of Acoustics Society Of America, 128, (2), p.646-653, ago.

MERINO, G. S. A. D. (2014) Metodologia para a Prática Projetual do Design: com base no Projeto Centrado no Usuário e com ênfase no Design Universal. 212 f. Tese (Doutorado) - Curso de Programa de Pós-graduação em Engenharia de Produção, Centro Tecnológico, Universidade Federal de Santa Catarina, Florianópolis.

Ministério da Saúde. (2014) Perda Auditiva Induzida por Ruído (Pair): Saúde doTrabalhador Protocolos de Complexidade Diferenciada. Brasília, 2006, disponível em

$<$ http://bvsms.saude.gov.br/bvs/publicacoes/protocolo_perda_auditiva.pdf $>$ Acesso em 25 out.

Ministério do Trabalho e do Emprego. (1978) NR 15: Atividades e Operações Insalubres-Anexo 1. São Paulo:

MORATA, T.C. (2007) Young people: Their noise and music exposures and the risk of hearing loss. Int J Audiol : 46: 111-12."

PALMA, D C. (1999) Quando o ruído atinge a audição. Porto Alegre.

PEREIRA, M L Duarte. Design Inclusivo(2009) Um Estudo de Caso: Tocar para Ver - Brinquedos para Crianças Cega e de Baixa Visão. 211 f. Dissertação (Mestrado) - Curso de Design e Marketing, Universidade do Minho.

PORTNUFF, C D.f; FLIGOR, B J \& AREHART, K H. (2011)“Teenage Use of Portable Listening Devices: A Hazard to Hearing?” Journal Of The American Academy Of Audiology, 22, (10), p.663-677.

PULLIN, Graham. Design meets disability. MIT Press, 2009.

QUINTANILLA-DIECK, M de L; ARTUNDUAGA, M A \& EAVEY, R D. (2009)“Intentional Exposure to Loud Music: The Second MTV.com Survey Reveals an Opportunity to Educate.” Journal of Pediatrics, 155 (4), p. 550555 , Out.

RUI, L R. \& STEFFANI, M. H.. "Física: Som e audição humana". Departamento de Física- IF-UFRGS e Planetário/PROREXT- UFRGS, Rio Grande do Sul.

SHARGORODSKY, J et al. (2010) "Change in Prevalence of Hearing Loss in US Adolescents." JAMA, 304, (7), p.772-778, ago.

SHIELD, B. (2006) "Evaluation of the Social and Economic Costs of Hearing Impairment". Hear-it Aisbl..

Sociedade Brasileira de Otologia (2014) SBO. Disponível em: <http://www.sbotologia.com.br/>. Acesso em: 25 ago. 
Design para saúde e qualidade de vida: desenvolvimento e avaliação de requisitos de projeto para fone de ouvido inclusivo.

TORRE III, P. (2008) 'Young Adults' Use and Output Level Settings of Personal Music Systems". Ear and Hearing, 29, p.791-799.

VOGEL, I. et al. (2008 ) "MP3 Players and Hearing Loss: Adolescents' Perceptions of Loud Music and Hearing Conservation." The Journal Of Pediatrics, 152, (3), p.400-404, mar.

ZHAO, F. et al. (2012 ) "Music exposure and hearing health education: A review of knowledge, attitude, and behaviour in adolescents and young adults." Health Educational Journal, 71 (6), p. 709-724. 